\title{
A survey of criteria for accredited publications
}

\author{
Cooper, Antony $\mathrm{K}^{\mathrm{a}, \mathrm{b}}$ \\ ${ }^{a}$ Smart Places, CSIR, Pretoria, South Africa, acooper@csir.co.za \\ ${ }^{b}$ Dept Geography, Geoinformatics \& Meteorology, University of Pretoria, Pretoria, South Africa
}

Keywords: International Cartographic Association, peer review, Education and Continuous Learning in Cartography

\begin{abstract}
:
The mission of the International Cartographic Association (ICA) is to promote the disciplines and professions of cartography and GIScience in an international context, with cartography being defined as the discipline dealing with the art, science and technology of making and using maps. Hence, it is unsurprising that the ICA community is diverse, covering national mapping agencies; other public entities at the global, regional, national and local levels; commercial and non-profit mapping organisations; artists, scientists and technologists in academia and research organisations; and users of spatial information - from around the world.
\end{abstract}

Each part of the ICA community has its own expectations of the ICA. For example, the way that contributions to ICA publications are measured or considered for job evaluations or obtaining funding are likely to differ within government organisations $v s$ universities $v s$ private companies. Further, these are also likely to differ between countries and even at the sub-national level. Our focus here is on the needs of academics and researchers managed by publish or perish criteria. This research will hopefully help ensure that the ICA's publications meet the minimum criteria around the world for accredited publications, and hence the needs of its members, to encourage publication in them. Even if it is possible for authors to fix things retrospectively because the journals, proceedings and other collections do not meet the specified criteria explicitly (even seemingly trivial ones), it can take a lot of effort by an author to provide justification for why their publication should receive accreditation.

This presentation will report on a survey of the national and affiliate members of the ICA. The issues covered by the survey include:

1) In your environment, what is an accredited publication?

2) How are different types of publications rated against one another, such as papers in books, journals, conference proceedings or popular magazines; editorials, invited papers or book reviews; or papers peer reviewed on full papers, on extended abstracts or on short abstracts?

3) What is meant by peer review, single blind peer review and double blind peer review, and do the differences matter for publication accreditation?

4) Does the number of referees matter?

5) How extensive does a referee's report have to be?

6) What about invited keynote speakers or invited panel members at conferences?

7) What criteria are used for determining the merits of publications for promotions?

8) For accreditation, are journals required to be on specified lists, such as those of the ISI, IBSS or Scopus?

9) What criteria are used for making grants for publications?

10) What criteria are used for providing travel funding to present at the International Cartographic Conferences (ICCs) and other conferences and events supported by the ICA?

11) What criteria are used for recognising the quality of publications and how the authors of such publications get recognised, etc? 
12) Are there any time restrictions on when papers need to be published to be accredited (such as the number of months after the purported year of publication)?

13) What criteria are used to ensure that the papers selected from a conference for inclusion in a journal or book are deemed to be more worthy than those in the peer-reviewed conference proceedings, if at all?

14) In such a situation, should the proceedings make reference to these selected papers, such as by including abstracts and/or DOIs?

15) Do you have any templates and guidelines for ensuring that publications are accredited, such as for the preface or introduction to a journal or a set of proceedings, to ensure that the rigour of the refereeing is obvious, present the rejection rate, acknowledging the referees and scientific committees, themes (this could be a problem if the theme is not considered to be worthy of research), etc?

16) What are the requirements for specifying the affiliations and contact details of authors, particularly where an author has more than one affiliation?

17) What are the requirements for ISBN or ISSN numbers, and/or DOIs, to ensure accreditation?

18) What are the requirements for open-access publishing?

19) What are realistic article processing charges (APCs) for academics and researchers in your community?

20) How easy is it to get funding to pay for APCs?

21) Should APCs be included in the conference fees for the ICCs, etc?

22) What are the requirements for publishing data sets?

23) Do you have any suggestions for the ICA's commissions and working groups on publishing the results of their research, etc?

24) How could the ICA improve its publications to meet your needs? 